\title{
Evaluation of nutritional characteristics of weaning food formulations
}

\author{
Malsawmtharzela* and A.K. Gupta
}

Department of Post Harvest Process and Food Engineering, College of Agricultural Engineering, Jabalpur (M.P.) India Email : mstharzela@gmail.com; write2drakg@gmail.com

SUMMARY :

Weaning food was developed in three different formulations viz., $\mathrm{F}_{1}$ (Malted wheat flour : Peanut flour: Banana flour :: $72 \%: 23 \%: 5 \%$ ), $\mathrm{F}_{2}$ (Malted wheat flour : Peanut flour: Banana flour :: $62 \%$ : $32 \%: 6 \%$ ) and $\mathrm{F}_{3}$ (Malted wheat flour : Peanut flour: Banana flour :: $68 \%: 26 \%: 6 \%$ ) at the lowest possible cost and in such a way that to meet and enriched the protein requirement of infant. The nutritional characteristic of developed weaning food was analyzed during the storage period of 90 days. The weaning food formulation with malted wheat flour, peanut flour and banana flour in the proportion of $62 \%: 32 \%: 6 \%$ was found best in terms of nutritional content during the study period of 90 days. It contains $15.37-16.07 \%$ protein, $11.56-12.33 \%$ fat, $2.07-2.20 \%$ ash, $63.23-63.29 \%$ carbohydrate and 418.6-428.2 kcal energy.

KEY WORDS : Weaning food, Protein, Nutritional characteristics, Storage

How to cite this paper : Malsawmtharzela and Gupta, A.K. (2019). Evaluation of nutritional characteristics of weaning food formulations. Internat. J. Proc. \& Post Harvest Technol., 10(2) : 23-27. DOI: 10. 15740/HAS/ IJPPHT/10.2/23-27. Copyright@ 2019: Hind Agri-Horticultural Society. 